\title{
A Comparative Study between Blood Donors and The General Population in Uttar Pradesh, India, to Analyse the Triggers for Donation
}

\author{
Suparna Dubey ${ }^{1 *}$ and Seema Dua ${ }^{2}$ \\ ${ }^{1}$ Department of Pathology, School of Medical Sciences and Research, Sharda University, G. Noida, U.P., India \\ ${ }^{2}$ Department of Transfusion Medicine, Super-speciality Pediatric Hospital and Postgraduate Teaching Institute, Noida, U.P., India
}

\begin{abstract}
Background: Despite its large population, access to safe blood is disproportionately low in India. To recruit more members from the general population into the pool of voluntary donors, it is essential to understand the differences in their knowledge, attitudes and practices; and utilise the existing resources to eliminate them.

Methods: A quasi-experimental study was conducted on 180 donors and an equal number of potential donors randomly selected from the community, using a structured questionnaire containing questions on attitudes and practices. Knowledge was assessed by interview by a single observer.

Results: Donors were found to have a highly significant difference $(\mathrm{p}<0.00001)$ from the general population in age, gender distribution, marital status and socioeconomic status and significant difference in educational level $(\mathrm{p}<0.05)$. Knowledge about blood donation practices was significantly higher in donors $(\mathrm{p}=0.0002)$. Replacement donors constituted $82.2 \%$ of the donor category, while voluntary donors dominated $(52.3 \%)$ in the community. Commonest reasons for non-donation in both groups included apathy. Misconceptions regarding pain, weakness, and increased chances of infection were prevalent. Donors were less likely to perceive blood donation as risky ( $<<0.00001)$. There was a highly significant difference in the attitude towards incentives $(p<0.00001)$, the donor group supporting and the community denouncing them. Replacement credits were the most popular incentive. In the donor group, a markedly higher ( $\mathrm{p}=0.0003)$ proportion had a history of previous donations ( $55 \%$ vs.36.1\%). Most of them had a higher number $(\mathrm{p}<0.00001)$ and greater frequency of donation. Donors generally reported a better donation experience $(\mathrm{p}=0.00003)$ and less complications than the general population $(\mathrm{p}=0.0002)$.
\end{abstract}

Conclusions: There is a need to recruit women and young donors from the community, and promote donor retention. Blood donation drives play important role in creating awareness, educating the masses and dispelling myths and misconceptions.

Keywords: Blood Donation, Blood Donors, Voluntary Donation

\section{Introduction}

Human blood is considered the "liquid of life" as it cannot be synthesised or substituted by any artificial means. The need for an adequate supply of safe blood has increased worldwide due to advancements in surgery and medical care. Simultaneously, increasingly stringent donor selection criteria to ensure decrease in transfusiontransmitted infections (TTI) have been enforced, which has led to an imbalance in the supply and demand of blood in many countries. ${ }^{[1]}$

A lower prevalence of TTIs has been reported among voluntary donors, with the lowest rates being found among regular donors. ${ }^{[2,3]}$ Therefore, the World Health Organisation (WHO) in 1975, laid down the goal of obtaining all blood supplies from voluntary, non-remunerated blood donors by 2020 and directed all countries to frame their national policies accordingly. ${ }^{[4]}$ Despite this, only $35 \%$ of the 192
Member States have a national blood policy, relevant legislation and one specific organization responsible for the national blood programme. ${ }^{[5]}$ According to the WHO, there is a great disparity in the access to safe blood. Only $45 \%$ of the global blood supply is collected in developing countries, which are home to more than $80 \%$ of the world's population. The average number of blood donations is 11 times higher in high income countries than in low-income countries. Moreover, 92\% of donations in developed countries are from voluntary unpaid donors as compared to about $67 \%$ in developing and transitional countries. ${ }^{[6]}$

In India, blood transfusion services are affected by the multiplicity of controls, with licensing being under Drug Controller General of India, policy under National and State Blood transfusion Councils and implementation with the states. ${ }^{[3,7]}$ A mere 2760 blood banks cater to a population of 1.33 billion. ${ }^{[8,9]}$ The annual requirement of blood in the 
country is estimated at 12 million units of blood, but only 10.9 million units were collected in the year 2015-16, 79\% of which was through non-remunerated donation. ${ }^{[10]}$ The disparity is even more conspicuousin the state of Uttar Pradesh (UP), where this study was conducted. Despite having the highest population, it has only 240 licensed blood banks, with a total annual collection of approximately 0.9 million units, ranking third nationally on both scores. ${ }^{[7,8,10]}$ Voluntary donation shows a dismal figure of $44 \%$, with only 6 out of 37 states ranking below it. ${ }^{[10]}$

To overcome this deficit, it is essential to understand the knowledge, attitudes and practices (KAP) of the existing donors and compare them with the community at large. The available resources can then be tailored to minimise the differences observed, thereby recruiting the general population to the pool of voluntary donors. In a country like India, where myths and superstitions pose a challenge to delivery of healthcare, KAP studies also help to identify the factors and myths that enable or prevent blood donation.

\section{Material and Methods}

This was a quasi-experimental study conducted by the Department of Pathology in a tertiary care centre in Greater Noida in Uttar Pradesh, India from March to September 2016 after obtaining permission from the Institutional Ethics Committee. Considering the blood donation rate of $12.7 \%$ in previous studies, taking a confidence level of $95 \%$ and a margin of error of $5 \%$, the calculated sample size is $167 .^{[11]}$ The study was conducted on two groups after taking informed written consent - 180 donors who donated blood in the institutional Blood Bank, and an equal number of potential donors randomly selected from the community, 90 from among the relatives accompanying patients and 90 from community visits.

A structured questionnaire was designed by the authors, keeping in mind the various parameters enumerated in the "Methodological Guidelines for Socio-cultural Studies on Issues Related to Blood Donation". ${ }^{[12]}$ It had three sections containing multiple-choice questions regarding donor demographics, source and level of knowledge on the topic, and attitudes, including factors which motivate or hinder blood donation, perceptions about risks involved and role of incentives. There was an additional section for assessment of donation practices, to be attempted only by participants who had previously donated blood, containing questions regarding the reasons for donation, number and frequency of previous donations, level of satisfaction with services at donation locations and details of complications, if any.

The questionnaire was administered individually to the participants and they were directed to complete all segments except that on knowledge. Thereafter each subject was interviewed about blood donation and transfusion by the same principal investigator, to avoid observer bias, and graded on a three-part Likert scale.

Statistics-The data collected was analysed using SPSS (version 17) software. Descriptive statistics, Chi-square test and, where applicable, Fisher's exact test, were used in this study to analyse the data.

\section{Results}

On comparing the demographic characteristics of the 180 donors with those of the general population, the differences were numerous and marked [Table 1]. Despite the apparent similarity in the mean age $(29.45 \pm 7.50$ vs. $28.09 \pm 10.43$ years) and age range (19-65 vs.18-60), the difference in age was highly significant $(\mathrm{p}<0.00001)$. It is noteworthy that the majority of donors $(97.2 \%)$ were below 45 years of age, whereas the distribution was more uniform in the case of the control group. Gender distribution, marital status and socioeconomic status were seen to have a highly significant $(\mathrm{p}<0.00001)$ and educational level a significant $(p<0.05)$ association with donation behaviour.

Two aspects of the knowledge about blood donation were studied - the level and the source of this information. Donors were significantly better informed than the general population $(p=0.000214)$ [Figure 1]. Friends played an important role, providing donation-related information to $35 \%$ of donors and $25 \%$ of the general public, but the main source of knowledge was the family in donors $(53.9 \%)$, and blood donation camps in the general community $(37.9 \%)$ [Figure 2].

The attitudinal assessment also revealed many differences [Table 2]. In this study, replacement donors, who formed the majority (82.2\%) in the donor group, were outnumbered by voluntary donors $(52.3 \%)$ in the community. Detailed questioning revealed that $2.2 \%$ of donors were actually commercial donors.

Among those who had not donated earlier, indifference or apathy, indicated by the statement "I was not asked to donate", was the commonest reason, both among the donor group and the general population. Lack of time was another important demotivating factor amongst donors (33.3\%) while fear contributed to $19.1 \%$ non-donations in the community. This included fear related to the procedure, like fear of injections in $2(1.7 \%)$ cases and fear bred by misconceptions like weakness in $9(7.8 \%)$, pain in 6 (5.2\%), and increased chances of infection in $5(4.3 \%)$ cases. $7.8 \%$ subjects in the general community had been rejected, the prime cause of deferral being anaemia in 7 $(6.1 \%)$ cases, followed by ongoing medication in $2(1.7 \%)$ cases, the records of which were not available. 
Perception of risk associated with blood donation was studied in all the subjects in both the groups and the difference found to be highly significant $(p<0.00001)$. The degree of risk perceived also varied greatly, with one case $(0.6 \%)$ each in the donor group labelling it as medium and low risk, and none grading it as high-risk. On the other hand, of the $44(24.4 \%)$ members of the general population who feel that it is a 'risky' procedure, it was graded as high, medium and low risk by $3(1.7 \%), 38$ (21.1\%) and $3(1.7 \%)$ persons respectively. However, both groups perceived similar risks- anaemia by both donors $(1.7 \%)$ and $38(21.1 \%)$ in the community, and infection by 6 $(3.3 \%)$ members of the public.

Attitudes towards the role of incentives, if any to, to promote blood donation, also varied considerably $(\mathrm{p}<0.00001)$. However, the incentives suggested by both groups were similar, with the majority- $160(88.9 \%)$ donors and 27 (15\%) community members proposing free replacement of blood for family or friends. Free blood test was proposed by $3(1.7 \%)$ donors and $10(5.6 \%)$ community members. Other suggestions from the general public included paid leave from work by $10(5.6 \%)$, free haematinics by 5 $(2.8 \%)$ and certificates by $2(1.1 \%)$ members.

A marked difference in blood donation practices was noted when previous donation behaviour in the donor group and the community was compared [Table 3]. The majority $(55 \%)$ of donors had donated earlier $(\mathrm{p}=0.00032)$. A large number of them had donated twice $(39.4 \%)$, thrice $(30.3 \%)$ or more times $(28.3 \%)$ prior to this donation. The highest number of previous donations was 21 . The fact that the last donation had occurred within the last six months in $79.8 \%$ of the cases indicates a higher frequency of donation. On the other hand, the donors in the community were generally casual donors, with the majority having donated only once $(64.6 \%)$, the highest number of donations being 6 , and $83.1 \%$ having donated more than six months back.

A statistically significant difference was observed in the donation experience $(\mathrm{p}=0.000034)$ and the post-donation complications reported by both groups $(p=0.000169)$. In the general population, $6(3.3 \%)$ donors complained of weakness and $3(1.7 \%)$ complained of pain at the phlebotomy site, both of which were self-resolving.

Table 1: Demographic profile of the study population.

\begin{tabular}{|c|c|c|c|c|}
\hline & & Donors (\%) & General population (\%) & $p$ value \\
\hline \multirow[t]{5}{*}{ Age (years) } & $18-25$ & $58(32.2)$ & $106(58.9)$ & $p<0.00001$ \\
\hline & $26-35$ & $95(52.8)$ & $39(21.7)$ & \\
\hline & $36-45$ & $22(12.2)$ & $12(6.7)$ & \\
\hline & $46-55$ & $4(2.2)$ & $21(11.7)$ & \\
\hline & $>55$ & $1(0.6)$ & $2(1.1)$ & \\
\hline \multirow[t]{2}{*}{ Gender } & Male & 178 (98.9) & $140(77.8)$ & $p<0.00001$ \\
\hline & Female & $2(1.1)$ & $40(22.2)$ & \\
\hline \multirow[t]{2}{*}{ Marital status } & Married & $99(55.0)$ & $156(86.7)$ & $p<0.00001$ \\
\hline & Unmarried & $81(45.0)$ & $24(13.3)$ & \\
\hline \multirow[t]{4}{*}{ Education } & Below $12^{\text {th }}$ std. & $108(60.0)$ & $130(72.2)$ & $p=0.018346$ \\
\hline & Graduate & $58(32.2)$ & $43(23.9)$ & \\
\hline & Postgraduate & $13(7.2)$ & $4(2.2)$ & \\
\hline & Professional & $1(0.6)$ & $3(1.7)$ & \\
\hline Family Income & $<10$ & $9(5.0)$ & $65(36.1)$ & $p<0.00001$ \\
\hline \multirow[t]{3}{*}{ (x103 per month) } & $10-50$ & $47(26.1)$ & $68(37.8)$ & \\
\hline & $50-100$ & 115 (63.9) & $27(15.0)$ & \\
\hline & $>100$ & $9(5.0)$ & $20(11.1)$ & \\
\hline
\end{tabular}

Table 2: Attitudes towards blood donation.

\begin{tabular}{|l|c|c|c|}
\hline & & Donors (\%) & General population (\%) \\
\hline Reasons for donation & Voluntarily & $28(15.6)$ & $34(52.3)$ \\
\hline & For relative/ friend & $148(82.2)$ & $31(47.7)$ \\
\hline Reasons for non-donation & For monetary gain & $4(2.2)$ & $0(0.0)$ \\
\hline
\end{tabular}




\begin{tabular}{|l|c|c|c|}
\hline & & Donors (\%) & General population (\%) \\
\hline & I was not asked to donate & $54(66.7)$ & $66(57.4)$ \\
\hline & I do not have time & $27(33.3)$ & $18(15.7)$ \\
\hline & I am afraid & $0(0.0)$ & $22(19.1)$ \\
\hline Risks due to blood donation & Others & $0(0.0)$ & $0(0.0)$ \\
\hline Should incentives be given? & Yes & $2(1.1)$ & $44(24.4)$ \\
\hline & No & $178(98.9)$ & $136(75.6)$ \\
\hline
\end{tabular}

Table 3: Practices of blood donation.

\begin{tabular}{|l|c|c|c|}
\hline & & Donors (\%) & General population (\%) \\
\hline Previous donation & Yes & $99(55.0)$ & $65(36.1)$ \\
\hline Number of donations & No & $81(45.0)$ & $115(63.9)$ \\
\hline & 1 & $2(1.1)$ & $42(64.6)$ \\
\hline & 2 & $39(39.4)$ & $11(16.9)$ \\
\hline & 3 & $30(30.3)$ & $8(12.3)$ \\
\hline Last donation & $\geq 4$ & $28(28.3)$ & $4(6.2)$ \\
\hline & $<6$ months back & $79(79.8)$ & $11(16.9)$ \\
\hline & 6 months-1 year & $20(20.2)$ & $31(47.7)$ \\
\hline Donation experience & $>1$ year back & $0(0.0)$ & $23(35.4)$ \\
\hline & Bad & $0(0.0)$ & $0(0.0)$ \\
\hline Sotisfactory & $10(10.1)$ & $24(36.9)$ \\
\hline & Good & $89(89.9)$ & $41(63.1)$ \\
\hline
\end{tabular}

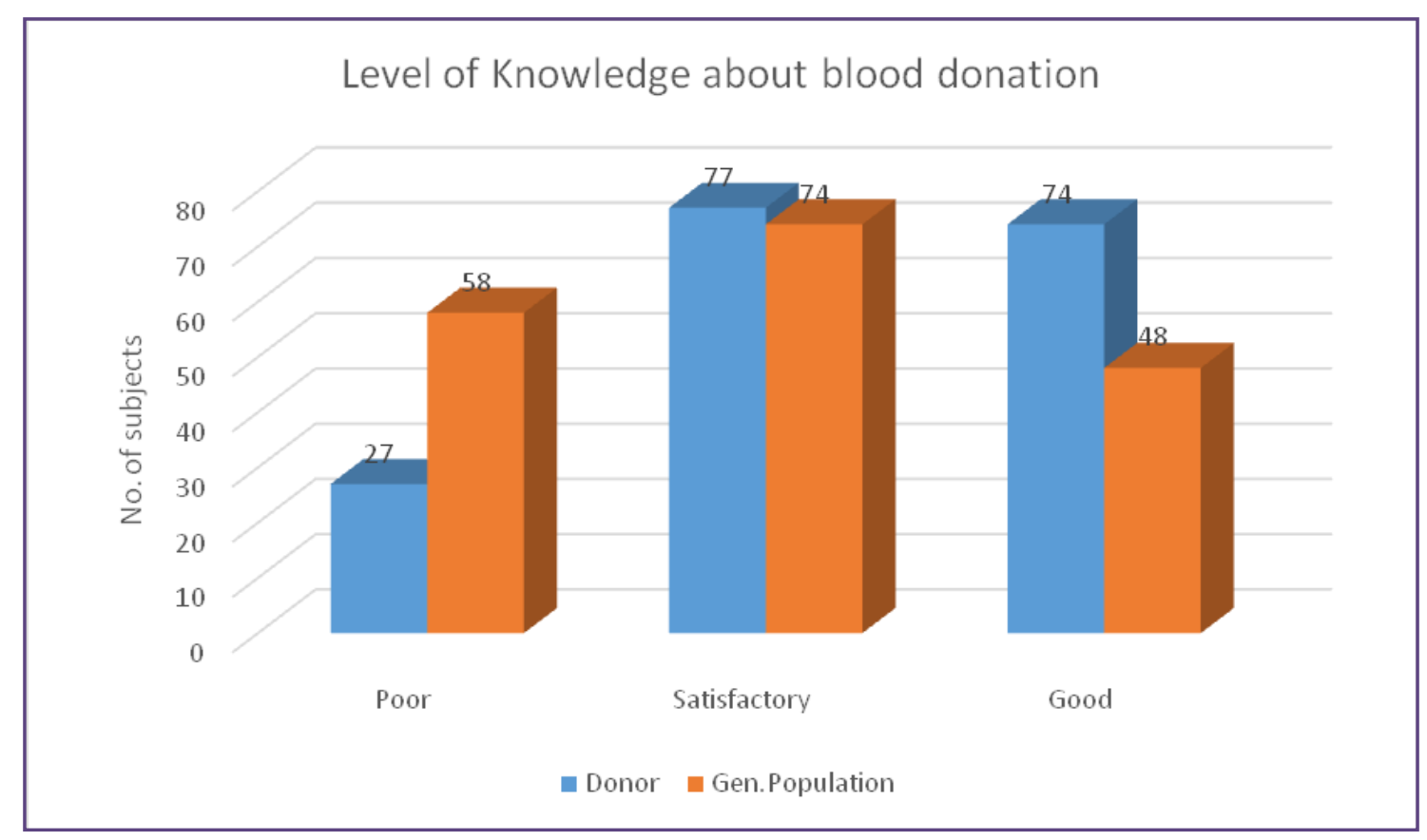

Fig. 1: Level of knowledge about blood donation. 


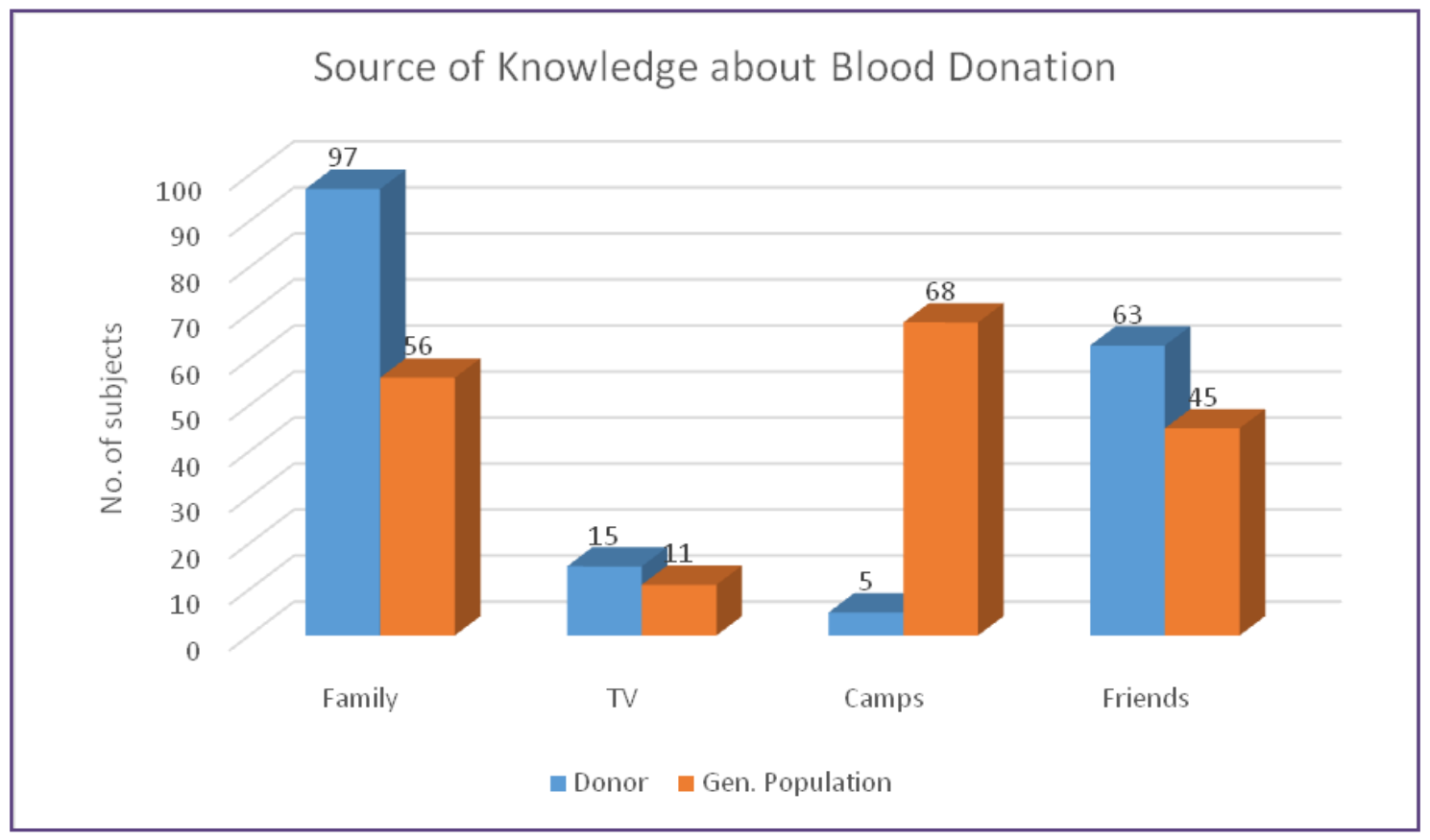

Fig. 2; Source of Knowledge about Blood Donation.

\section{Discussion}

India is among the first in the South-East Asia region (SEAR) to attempt a reorganisation of its blood transfusion system. ${ }^{[13]}$ In its landmark judgement of 1996, the Supreme Court of India banned professional blood donation, introduced mandatory licensing of blood banks, and directed the government, through National AIDS Control Organization (NACO), to establish the National and State Blood Transfusion Councils (NBTC/SBTC), to develop policies and programmes for improvements in blood banks. In 2002, NACO adopted the WHO Guidelines on the Clinical Use of Blood. In 2003, the Government of India framed and adopted the National Blood Policy (NBP). In 2013, India was among the 51 countries of WHO participating in the 'Rome declaration' on 'achieving self-sufficiency in safe blood and blood products based voluntary non-remunerated donation.' Despite this, there is limited access to safe blood in rural areas in states like UP, Uttarakhand, Jharkhand, Bihar and Chhattisgarh. ${ }^{[14]}$ Hence this study was planned in a non-profit tertiary-care centre in a semi-urban region in UP, which mainly caters to the adjacent rural population.

This study demonstrated that young, unmarried males with a higher educational and socioeconomic level tend to be donors. India has a high proportion of youth. However the majority (52.8\%) of the donors were of the age group 26-35 years, similar to a study in north-east India, ${ }^{[12]}$ but in contrast to studies in urban north India ${ }^{[14,15]}$ and south
India, where subjects below 25 years formed the largest proportion $(61.3 \%)$ of voluntary donors. ${ }^{[16]}$ This shows that the large pool of potential donors below 25 years of age $(58.9 \%)$ has not been tapped in the rural areas of north and north-east India.

Males have shown greater donation behaviour in almost all studies in developing countries like India ${ }^{[12,14-17]}$ and SEAR,,${ }^{[13]}$ Nigeria, ${ }^{[18]}$ Israel,,${ }^{[19]}$ Iran ${ }^{[20]}$ and Greece ${ }^{[21]}$ which is not the case in western countries. ${ }^{[5]}$ In our study, $98.9 \%$ of the donors were males, similar to but higher than the values of $93 \%,{ }^{[16]} 90 \%,{ }^{[14]} 84.2 \%,{ }^{[12]}$ and $76 \%,{ }^{[15]}$ in other Indian studies. This may be attributed to multiple factorshigh rates of illiteracy, which promote myths, sociocultural taboos, which restrict mobility, and malnutrition, anaemia and multiple pregnancies, which cause deferral in women, especially in rural areas.

In our study $55 \%$ of the donors were married but unmarried men were more likely to donate $(p<0.00001)$, which was similar to other studies. ${ }^{[15,17,22]}$ Owing to a high school dropout rate in India, the majority of subjects in both categories had education below the twelfth standard. However, donors were likely to have a higher educational level ( $\mathrm{p}<0.05$ ), with $40 \%$ of them having attended college. Similarly they were likely to enjoy a higher socio-economic status $(\mathrm{p}<0.00001)$. This association of donation behaviour with education ${ }^{[12,14,16,17,22]}$ and income ${ }^{[12]}$ has been welldocumented, but it is noteworthy that both these factors are dependent variables, and one may well lead to the other. 
Knowledge about Blood Donation: The fact that donors have a significantly higher $(\mathrm{p}<0.05)$ level of knowledge about blood donation services is supported by numerous other studies ${ }^{[14,15,20,23]}$ and refuted by some. ${ }^{[2]}$ However, our study demonstrated that the knowledge level in a majority of subjects in both groups was just satisfactory. Only $41.1 \%$ of donors and $26.7 \%$ of the general population had a high level. There is a need to act upon this lacuna by education programmes.

The peer group was useful in dissemination of information, and possibly motivation, to all, but the majority of donors were motivated by their family, and the general public by blood donation camps organised in the region. The important role of television and media, highlighted in other studies, ${ }^{[15]}$ have a lesser impact in rural areas. However this study shows that blood donation drives and propaganda by blood banks may contribute significantly in educating the masses, thereby recruiting them into the donor pool. ${ }^{[24]}$

Attitudes Towards Blood Donation: Most developing and transitional countries depend heavily on replacement donation, [13,14,18,25-27] and India is no exception. In our study, $82.2 \%$ of the donors were replacement donors, similar to $93.3 \%$ in another north Indian study. ${ }^{[14]}$ It is worth mentioning here that the donor group in this study comprised of only those donors who visited the blood bank in the hospital, possibly driven by a need for replacement credit; proportion of voluntary donations is much higher in blood donation camps but no such camps were organised during this period. However, voluntary donors comprised $52.3 \%$ of donors in the community, similar to $47.2 \%$ in a study from south India. ${ }^{[16]}$

This indicates that members of the community are motivated for voluntary donation by blood donation drives, but not sufficiently to visit blood banks of their own accord to donate blood. Other studies have also cited the role of drives or reminders by blood bank personnel in motivating voluntary donation. ${ }^{[21,24]}$

The presence of $2.2 \%$ commercial donors also reveals that though donation for money is illegal, ${ }^{[3]}$ such donors often find entry under the disguise of replacement donors. [12,13]

The commonest reason for not donating blood earlier, both among the donor group (66.7\%) and the general population $(57.45 \%)$, was an apathetic rejoinder- 'I was not asked to donate blood." A similar attitude of indifference has been noted in many Indian ${ }^{[14,15]}$ and global studies as the chief deterrent. ${ }^{[18,21]}$ This points towards a lack of awareness of the shortage of blood and its life-saving properties. Convenience-related issues like lack of time, distance of the blood bank, transport issues, have been cited as causes in many studies ${ }^{[14,15,25,28]}$ and refrained $33.3 \%$ of the present donors in this study from donating earlier. This shows that donations can be sought by arranging blood donation camps at convenient locations. Fear, much of it caused by misconceptions regarding pain and syncope during the procedure on one hand, and myths about weakness, loss of immunity, transmission of HIV and infertility on the other, are prevalent, both in India ${ }^{[13-16]}$ and abroad. [20, 22,23,26-28] They contributed to $19.1 \%$ detentions in the community, but strangely, no subject reported fear of infertility, which has been reported in all erstwhile Indian studies. ${ }^{[13-15]}$ Hopefully, this myth has been busted, at least in this region. Furthermore, steps to eradicate malnutrition and the resultant anaemia, which has been the major cause for deferral, will help not only in nation-building, but in recruiting more female donors.

This study showed that donors were less likely to view blood donation as a risky procedure $(\mathrm{p}<0.00001)$, and if they did, they were likely to grade the degree of risk lower than the general population. This has been documented in previous studies. ${ }^{[16]}$ Much of this perception of 'risk' is due to the myths and misconceptions mentioned earlier. These issues need to be addressed and irrational fears allayed.

Our study also unveiled a highly significant difference in the attitude towards incentives for blood donation $(\mathrm{p}<0.00001)$, the donor group promoting and the community denouncing them. While interpreting this data, we must however, bear in mind the fact, that the donor group consisted chiefly $(82.2 \%)$ of replacement donors, who understandably asked for free blood for family or friends as an incentive (in 88.9\% cases). On the other hand, the donors in the community were mainly $(52.3 \%)$ voluntary donors, and therefore shunned the idea of incentives (in $70 \%$ cases). Some studies supporting incentives can be found in literature. ${ }^{[12]}$

However, like all other studies, our study also showed replacement credits to be the most popular incentive. $[12,14,15,21,25]$ Other suggestions, which have been proposed in other studies too, include free tests, ${ }^{[15,21]}$ paid leave, ${ }^{[12,21]}$ free haematinics and certificates. ${ }^{[12,14]}$

Practices of Blood Donation: A far more important issue than donor recruitment is donor retention. Only 5-10\% donors in the SEA Region are repeat donors. ${ }^{[13,16]}$ In our study, most of the donors in the donor group were seen to be regular donors, with a history of past donations $(p<0.05)$ and boasting of a significantly greater number $(p<0.00001)$ and higher frequency of blood donations. The donors in the community were generally casual donors-64.6\% had donated once, $16.9 \%$ twice and $6.2 \%$ thrice, which is comparable to the figures of $68 \%, 13.3 \%$ and $6.7 \%$ registered in the general population in a similar 
study in urban north India. ${ }^{[14]}$ It is essential to prevent the dropout of these casual donors and convert the oncedonors to regular voluntary donors, to be able to attain the goal of $100 \%$ voluntary non-remunerated blood donation laid down by the WHO.

In this study, donors had a significantly better donation experience than the general population $(p=0.000034)$, similar to other studies. ${ }^{[15]}$ This is actually a reflection of the fact that a positive donation experience increases the probability of a repeat donation, ${ }^{[29]}$ Thus, it is important to ensure that the donation process is hassle-free, the donation area has a pleasant atmosphere and the staff is courteous. Only $3.3 \%$ donors from the community complained of minor complications $(p<0.05) .{ }^{[16]}$ Follow-up in the community is important to emphasize the transient and self-resolving nature of these complaints.

This study suffers from the limitation of sampling bias. Larger studies may further help evaluate the differences in the blood donating mindset between the donors and the general population.

\section{Conclusion}

The majority of donors in India are replacement donors. Young, unmarried males with a higher educational and socioeconomic level and having a greater knowledge of blood donation practices tend to donate blood. There is a need to recruit women and potential donors below the age of 25 years into the pool of voluntary donors. This is possible by blood donation drives in the community, which will reach out to the masses, create an awareness about the importance of blood donation, serve as reminders, educate them, and dispel the prevalent myths and misconceptions. It is important to ensure convenience of blood donation services and a hassle-free procedure for retention of the recruited donors as regular voluntary donors.

\section{References}

1. Riley W, Schwei M, McCullough J. The United States' potential blood donor pool: estimating the prevalence of donor-exclusion factors on the pool of potential donors. Transfusion. 2007;47:1180-8.

2. World Health Organization. Universal Access to Safe Blood Transfusion. Geneva, Switzerland:WHO; 2008. Available from: http://www.who.int/bloodsafety/publications/ UniversalAccesstoSafeBT.pdf. Accessed on 10 April 2017.

3. Nair SC, Mammen JJ. Repeat voluntary non-remunerated blood donor is the best quality indicator for blood safety. Indian J Med Res. 2015;141:749-52.

4. WHA28.72 Utilization and supply of human blood and blood products. Available from: www.who.int/bloodsafety/ en/WHA28.72.pdf Accessed on 10 April 2017.
5. Utilisation and supply of human blood and blood products. Available from: http://www.who.int/bloodsafety/en/ WHA28.72.pdf. Accessed on 10 April 2017.

6. Blood safety. Available from: http://www. who.int/bloodsafety/Strategi c P 1 an 2008 2015AccessSafeBloodTransfusion.pdf. Accessed on 10 April 2017.

7. Blood-transfusion-services. http://www.naco.gov.in/ NACO/Blood_Safety/Blood_Safety_More/ Accessed on 10 April 2017.

8. Blood Banks in India. Available from: http://www.cdsco. nic.in/writereaddata/BLOOD BANKS INDIA feb 2015.pdf Accessed on 10 April 2017.

9. Total Population- Both Sexes. World Population Prospects, the 2015 Revision. https://esa.un.org/unpd/wpp/ Accessed on April 10, 2017.

10. Blood Transfusion Services (BTs) data for FY 2015-16. Available from: http://www.naco.gov.in/NACO/Divisions/ Blood_Safety/Accessed on April 10, 2017.

11. Policy on research for health. Available from: http://www1. paho.org/hq/dmdocuments/2009/F4942/ Accessed on April 10, 2017.

12. Shenga N, Pal R, Sengupta S. Behavior disparities towards blood donation in Sikkim, India. Asian J Transfus Sci. 2008 Jul; 2: 56-60.

13. Bharucha ZS. Donor management in South-East Asia region (SEAR). DevBiol. 2005;120:145-53.

14. Sharma R, Madan N, Venkatesh S, Ichhpujani RL, Lal S. Factors influencing blood donations and the rational use of blood. J Commun Dis. 2010;42:185-90.

15. Dubey A, Sonker A, Chaurasia R, Chaudhary R. Knowledge, attitude and beliefs of people in North India regarding blood donation. Blood Transfus. 2014;12Suppl 1:s21-7.

16. Uma S, Arun R, Arumugam P. The Knowledge, Attitude and Practice Towards Blood Donation Among Voluntary Blood Donors in Chennai, India. J Clin Diagn Res. 2013; 7: 1043-1046.

17. Raghuwanshi B, Pehlajani NK, Sinha MK. Voluntary Blood Donation among Students - A Cross-Sectional Study on Knowledge and Practice vs. Attitude. J Clin Diagn Res. 2016;10:EC18-EC22.

18. Sekoni AO, Balogun MR, Odukoya OO, Inem V, Onigbogi OO. Blood donation practices and willingness to donate among residents of an urban slum in Lagos Nigeria. Niger Postgrad Med J. 2014;21:21-7.

19. Weinberg I, Zarka S, Levy Y, Shinar E. Why would young people donate blood? A survey-based questionnaire study. Vox Sang. 2009;96:128-32.

20. Shahshahani HJ, Yavari MT, Attar M. Knowledge, attitude and practice study about blood donation in the urban population of Yazd, Iran, 2004. Transfus Med. 2006;16:403-9. 
21. Marantidou O, Loukopoulou L, Zervou E, Martinis G, Egglezou A, Fountouli P,et al. Factors that motivate and hinder blood donation in Greece. Transfus Med. 2007; 17:443-50.

22. Vásquez M, Ibarra P, Maldonado M. Blood donation: knowledge and attitudes of a university population in Chile. Rev Panam Salud Publica. 2007;22:323-8.

23. Wiwanitkit V. Knowledge about blood donation among a sample of Thai university students. Vox Sang. 2002;83:97-9.

24. Glynn SA, Kleinman SH, Schreiber GB, Zuck T, Combs SM, Bethel J,et al. Motivations to donate blood: demographic comparisons. Transfusion. 2002;42:216-25.

25. Sampath S, Ramsaran V, Parasram S, Mohammed S, Latchman S, Khunja R,et al. Attitudes towards blood donation in Trinidad and Tobago. Transfus Med. 2007; 17:83-7.

26. Alam M, MasalmehBel D. Knowledge, attitudes and practices regarding blood donation among the Saudi population. Saudi Med J. 2004;25:318-21.

27. Salaudeen AG, Odeh E. Knowledge and behavior towards voluntary blood donation among students of a tertiary institution in Nigeria. Niger J Clin Pract. 2011;14(3):303-7.

28. Mathew SM, King MR, Glynn SA, Dietz SK, Caswell SL, Schreiber GB. Opinions about donating blood among those who never gave and those who stopped: a focus group assessment. Transfusion. 2007;47:729-35.

29. Schlumpf KS, Glynn SA, Schreiber GB, Wright DJ, Randolph Steele W, Tu Y,et al. Factors influencing donor return. Transfusion. 2008;48:264-72.

*Corresponding author:

Dr. Suparna Dubey, H-20, Kailash Colony, N. Delhi-110048, India.

Phone: +91 9311310507

Email: drsprn@gmail.com

Date of Submission : 19.04.2017

Date of Acceptance : 21.08.2017

Financial or other Competing Interests: None.
Date of Publication : 19.12.2017 